\title{
Sodium fluorescence Doppler lidar to measure atmospheric temperature in the mesopause region
}

\author{
HU Xiong ${ }^{1}$, YAN ZhaoAi ${ }^{1,2 *}$, GUO Shang Yong ${ }^{1}$, CHENG YongQiang $^{1}$ \& GONG JianCun ${ }^{1}$ \\ ${ }^{1}$ Center for Space Science and Applied Research, Chinese Academy of Sciences, Beijing 100190, China; \\ ${ }^{2}$ Graduate University of Chinese Academy of Sciences, Beijing 100049, China
}

Received August 19, 2010; accepted November 9, 2010

\begin{abstract}
A sodium fluorescence Doppler lidar system has been developed to measure environmental parameters of the middle and upper atmosphere. The lidar system mainly comprises a transmitter system, receiver system, data acquisition and control system and data analysis system. A narrowband $589 \mathrm{~nm}$ laser is used to excite sodium atoms in the mesopause region. Excitation of the sodium atoms results in resonance fluorescence, which is collected by the receiver. The temperatures in the mesopause region (about $75-105 \mathrm{~km}$ ) can be derived by analyzing the Doppler-broadened width of the sodium fluorescence. Observations were made with the lidar system, and the number density of sodium atoms and atmospheric temperature profiles were extracted from the observation data. Comparisons of the lidar temperatures and TIMED/SABER temperatures show good agreement, illustrating the reliability of the sodium fluorescence Doppler lidar measurements.
\end{abstract}

Doppler lidar, sodium resonance fluorescence, mesospause temperature

Citation: Hu X, Yan Z A, Guo S Y, et al. Sodium fluorescence Doppler lidar to measure atmospheric temperature in the mesopause region. Chinese Sci Bull, 2011, 56: 417-423, doi: 10.1007/s11434-010-4306-x

The mesopause region is an area of strong coupling between the lower and upper atmosphere. Its temperature structure greatly affects atmospheric stability, energy transfer, atmospheric chemical processes and dynamical behaviors. The mesopause region is the coldest on Earth. Noctilucent clouds have been recently found to spread from polar to mid-latitude and high-latitude regions, possibly owing to mesospheric cooling in response to global climate change. To explore this possibility, it is important to measure the temperature structure of the mesopause.

There are several kinds of lidar for measuring atmospheric temperature, such as Rayleigh scattering lidar [1-3], Raman scattering lidar [4,5], resonance fluorescence Doppler lidar [6,7], high spectral resolution lidar [8,9] and differential absorption lidar [10]. Sodium fluorescence Doppler lidar is mainly used to measure the atmospheric temperature and wind in the mesopause region.

*Corresponding author (email: yanza@ 126.com)
Sodium fluorescence lidar, potassium fluorescence lidar, iron Boltzmann lidar and calcium fluorescence lidar employ sodium, potassium, iron and calcium fluorescence respectively in the mesopause region for sounding of the middle and upper atmosphere [7,11]. In 1969, Bowman et al. [12] completed the first lidar observation of mesospheric sodium atoms using a tunable laser. The first observation of the sodium hyperfine structure in the middle and upper atmosphere was reported by Gibson et al. [13] in 1979, establishing the possibility of mesopause temperature measurements with narrowband resonance fluorescence lidar. The first sodium fluorescence Doppler lidar system for temperature measurements was operated routinely at Andoya, Norway in 1985 [14]. A more advanced narrowband sodium fluorescence lidar system using a two-frequency technique was developed through collaboration between Colorado State University [15] and University of Illinois at Urbana and Champaign [16] in 1990, achieving higher accuracy. Thereafter, Colorado State University developed a three-frequency so- 
dium fluorescence Doppler lidar system employing the laser stabilization technique and the frequency modulation technique to simultaneously measure wind and temperature [7,18]. In 2002, the Colorado State University sodium fluorescence Doppler lidar system was upgraded to a two-beam system to realize simultaneous atmospheric temperature and wind measurements [19]. In 2006, this lidar system was upgraded to a three-beam system to provide measurements of the atmospheric momentum flux as well as the atmospheric temperature and wind [20].

In China, Wuhan Institute of Physics and Mathematics, Chinese Academy of Sciences, developed a Rayleigh/sodium fluorescence lidar system in 1996 [21]. At present, Wuhan University, University of Science and Technology of China, China Research Institute of Radio Wave Propagation, and Center for Space Science and Applied Research (CSSAR), Chinese Academy of Sciences, are observing the middle and upper atmosphere with sodium fluorescence lidar systems at Wuhan [22], Hefei [23], Qingdao, Beijing and Hainan. However, these lidar systems do not employ Doppler techniques and can only measure the density profiles of sodium atoms and not the temperature or wind. Wuhan University developed an iron Boltzmann lidar system to measure the mesopause temperature in 2006 [24].

To measure the mesopause temperature and wind simultaneously, CSSAR has investigated the principle of the sodium fluorescence Doppler lidar and the method for retrieving atmospheric parameters, simulated the lidar backscattering photon signal $[25,26]$, and measured the saturated fluorescence spectrum of sodium atoms [27]. CSSAR has developed a technique for stabilizing the laser frequency employing the saturated fluorescence spectrum, and in turn, a narrowband, three-frequency sodium fluorescence Doppler lidar system. This is the first sodium fluorescence Doppler lidar system in China. Observations of the middle and upper atmosphere have been made with this lidar in Beijing. The lidar measurement principle and components, and the observed temperature results and their comparisons with TIMED/SABER temperature results, are introduced in this paper.

\section{Measurement principle of sodium fluores- cence Doppler lidar}

A metal layer containing sodium atoms exists at about $75-105 \mathrm{~km}$ altitude. The sodium atom layer as a tracer has the same temperature as the background atmospheric temperature. In the mesopause region, the Doppler-broadened width of the sodium fluorescence is a function of temperature. A $589 \mathrm{~nm}$ laser excites the sodium atoms so that there is resonance fluorescence. The temperature can be obtained by measuring the Doppler broadening of the fluorescence. The use of sodium fluorescence Doppler lidar to measure wind and temperature is detailed in the literature $[7,17,26]$.
A simple description is given below.

The sodium $D_{2}$ line is used in sodium fluorescence Doppler lidar. Figure 1 is an energy-level diagram of sodium $D$ transitions. The $D_{2}$ line is the transition from $3^{2} \mathrm{p}_{3 / 2}$ to $3^{2} \mathrm{~s}_{1 / 2}$, and the corresponding wavelength is $589.158 \mathrm{~nm}$ in a vacuum. In the case of the $D_{2}$ line hyperfine structure, the excited state $3^{2} \mathrm{p}_{3 / 2}$ splits into four levels.

In the mesopause region, the Doppler-broadened width for the sodium atom is proportional to the square root of the absolute temperature and inversely proportional to the square root of the atomic mass. It can be expressed as

$$
\sigma_{D}=\sqrt{\frac{k_{B} T}{M \lambda_{0}^{2}}},
$$

where $k_{B}$ is the Boltzmann constant, $T$ is temperature, $M$ is the mass of the atom and $\lambda_{0}$ is the central wavelength.

The sodium Doppler-broadened lineshape is $[6,7]$

$$
g(v)=\frac{1}{\sqrt{2 \pi} \sigma_{D}} \sum_{n=1}^{6} A_{n} \exp \left(-\frac{\left[v_{n}-v\left(1-\frac{v_{R}}{c}\right)\right]^{2}}{2 \sigma_{D}^{2}}\right),
$$

where $\sigma_{D}$ is the root-mean-square width of the Dopplerbroadened line, $v_{n}$ and $A_{n}$ are the central frequencies and the line strengths of six electric-dipole-allowed $D_{2}$ transitions, $v$ is frequency, $v_{R}$ is the radial velocity of the sodium atom moving away from the laser source and $c$ is the speed of light. The main parameters of the $D_{2}$ line hyperfine structure are listed in Table 1.

Sodium resonance fluorescence is induced by the laser. The lineshape of the resonance fluorescence spectrum is a convolution of the atom Doppler-broadened lineshape and laser lineshape $g_{L}(v)$, which can be expressed as

$$
G(v)=\int g\left(v-v^{\prime}\right) g_{L}\left(v^{\prime}\right) \mathrm{d} v^{\prime} .
$$

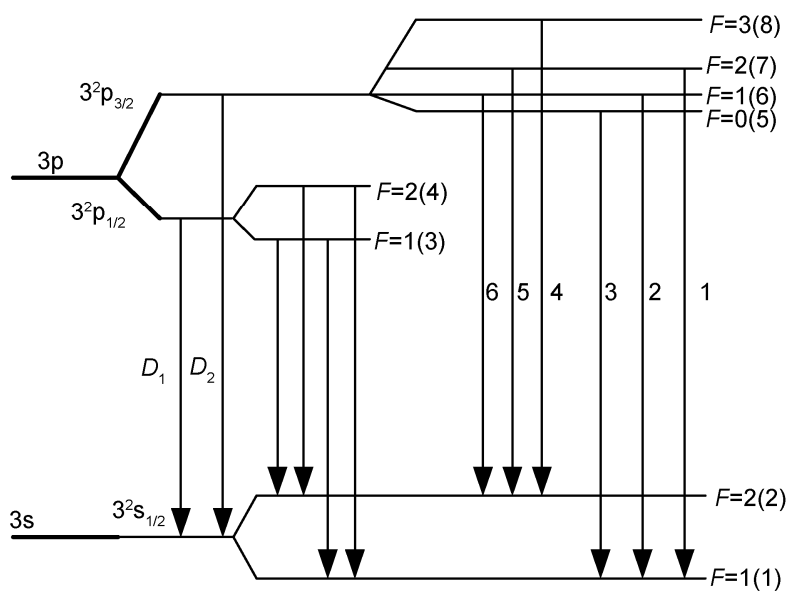

Figure 1 Energy levels of sodium $D$ transitions. 
Usually, the laser lineshape $g_{L}(v)$ is Gaussian with a width $\sigma_{L}$, which is measured as about $140 \mathrm{MHz}$ for the present lidar system.

From eqs. (2) and (3), it is clear that the atmospheric temperature determines the linewidth of the sodium fluorescence spectrum, and that the radial wind speed determines the Doppler shift. Figure 2 shows sodium fluorescence spectrum lineshapes for different temperatures when the radial wind speed is zero.

Two independent ratios of echo signals can be obtained when transmitting three-frequency narrowband laser pulses. The linewidth and Doppler shift can be measured simultaneously using these two ratios, from which the atmospheric temperature and radial wind speed can be retrieved simultaneously. This technique is referred to as the three-frequency-ratio Doppler technique $[7,17,26]$. Three frequencies $f_{0}, f_{+}$, and $f_{-}$used by the CSSAR lidar system correspond to the peak and two wings of the $D_{2 \mathrm{a}}$ line; i.e. $f_{+}=f_{0}+630 \mathrm{MHz}$ and $f_{-}=f_{0}-630 \mathrm{MHz}$. The echo signals due to atmospheric backscattering and resonance fluorescence are denoted by $N\left(f_{0}\right), N\left(f_{+}\right)$and $N\left(f_{-}\right)$for the three frequencies $f_{0}$, $f_{+}$and $f_{-}$respectively. The ratio $R_{T}$ is defined as

$$
R_{T}=\frac{N\left(f_{+}\right)+N\left(f_{-}\right)}{N\left(f_{0}\right)} .
$$

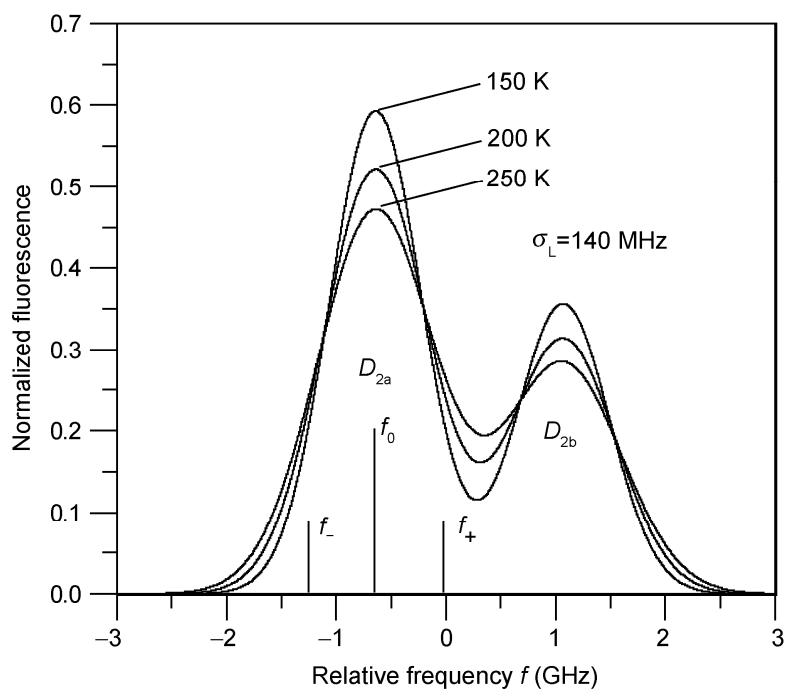

Figure 2 Fluorescence of the sodium atom at different temperatures.

Table 1 Parameters of $\mathrm{Na} \mathrm{D}_{2}$ hyperfine transitions [6]

\begin{tabular}{cccc}
\hline $\begin{array}{c}\text { Transition } \\
\text { line }\end{array}$ & $\begin{array}{c}\text { Transition } \\
n\end{array}$ & $\begin{array}{c}\text { Frequency offset } \\
(\mathrm{GHz}) v_{n}\end{array}$ & $\begin{array}{c}\text { Relative line } \\
\text { strength } A_{n}\end{array}$ \\
\hline \multirow{3}{*}{$D_{2 \mathrm{~b}}$} & 1 & 1.0911 & $5 / 32$ \\
& 2 & 1.0566 & $5 / 32$ \\
& 3 & 1.0408 & $2 / 32$ \\
\hline \multirow{2}{*}{$D_{2 \mathrm{a}}$} & 4 & -0.6216 & $14 / 32$ \\
& 5 & -0.6806 & $5 / 32$ \\
& 6 & -0.7150 & $1 / 32$ \\
\hline
\end{tabular}

The relation between the ratio $R_{T}$ and the atmospheric temperature $T$ is presented in Figure 3 . Therefore, by measuring the ratio $R_{T}$, the temperature can be estimated from Figure 3.

The principle and equations of radial wind speed measurement using the three-frequency ratio technique are detailed in the literature and are thus not presented here.

\section{Sodium fluorescence Doppler lidar}

The CSSAR sodium fluorescence Doppler lidar system mainly consists of a transmitter system, receiver system, data acquisition and control system and data analysis system. Figure 4 is a schematic diagram of the lidar system.

The transmitter system generates three-frequency laser pulses with high stability and narrow linewidths. In the transmitter, a ring-cavity dye laser emits a continuous-wave

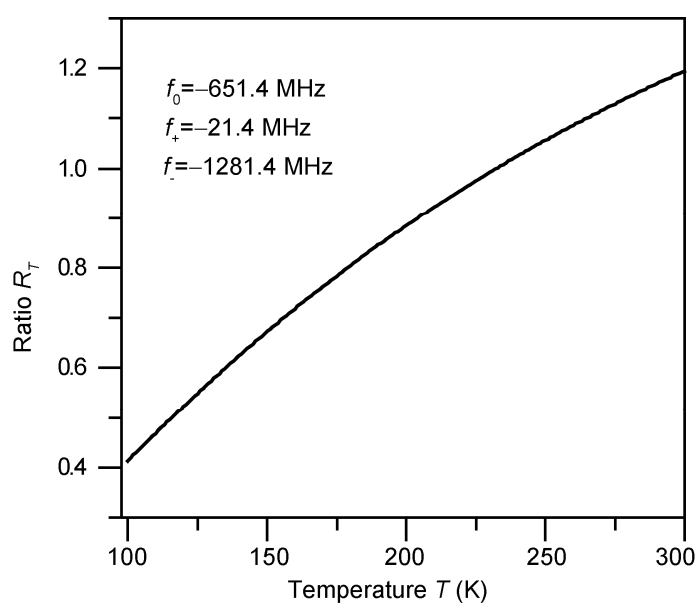

Figure 3 Ratio $R_{T}$ versus temperature $T$.

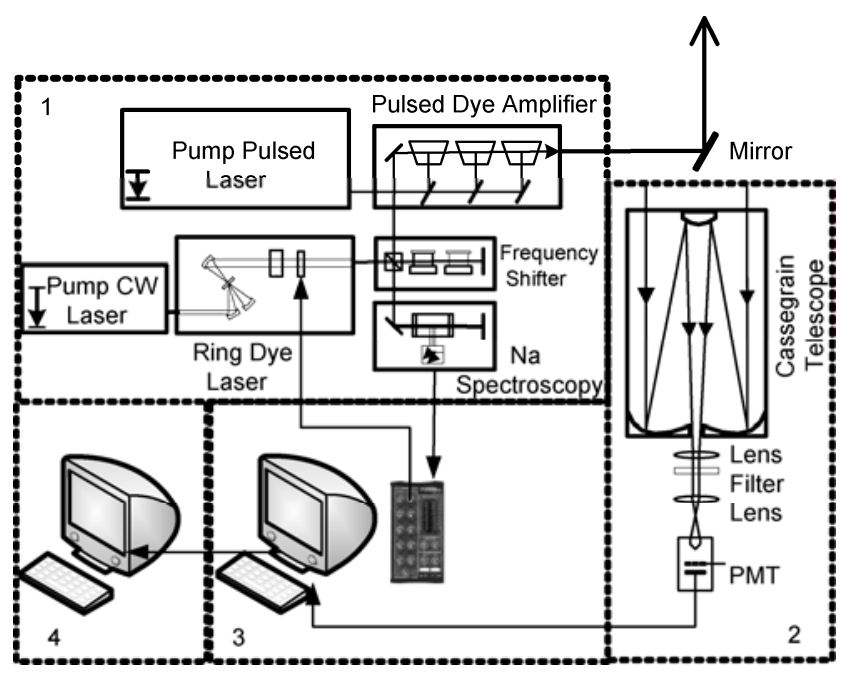

Figure 4 Schematic diagram of the sodium fluorescence Doppler lidar system. 1, Transmitter system; 2, receiver system; 3, data acquistion and control system; 4, data processing system. 
narrowband laser beam with the help of frequency-selective elements such as a birefringent filter and Fabry-Perot etalons. The Pound-Drever-Hall frequency stabilization technique is employed for the laser. The continuous-wave laser linewidth is about $100 \mathrm{kHz}$. The laser frequency drifts owing to ambient temperature changes and piezo-actuator relaxation. To compensate the drift and stabilize the laser frequency at the peak of the sodium $D_{2 \mathrm{a}}$ line, sodium-atom Doppler-free saturation fluorescence spectroscopy is employed [27,28]. A frequency shifter system produces threefrequency $\left(f_{0}, f_{+}\right.$and $\left.f_{-}\right)$laser light successively. The system has two acousto-optic frequency shifters: one to shift the laser frequency by $+630 \mathrm{MHz}$ and the other to shift the frequency by $-630 \mathrm{MHz}$. Finally, the pulsed dye amplifier outputs a $30 \mathrm{~Hz}, \sim 1 \mathrm{~W}$ pulsed laser beam.

A Cassegrain telescope collects atmosphere backscattering photons in the receiver system. A photomultiplier tube detects photons while the background noise is rejected by optical filters. At present, a $40 \mathrm{~cm}$ diameter telescope is mounted to receive signals in the vertical direction. In the near future, three $1 \mathrm{~m}$ diameter telescopes will receive echoes from the zenith, $20^{\circ}$ east of the zenith and $20^{\circ}$ north of the zenith; thus, the temperatures and radial wind speeds in these three directions will be obtained simultaneously and three-dimensional winds will be estimated.

In the data acquisition and control system, a photon counter records the number of pulses outputted by the photomultiplier tube, and a digital pulse generator controls the frequency shifter system, lasers and photon counter.

The data analysis system retrieves atmospheric parameters from the recorded photon counts.

The current system parameters of the lidar are listed in Table 2.

\section{Observation results and comparison with TIMED/SABER results}

Observations were made at Beijing $\left(40.0^{\circ} \mathrm{N}, 116.3^{\circ} \mathrm{E}\right)$ using the sodium fluorescence Doppler lidar system. The first sodium fluorescence signal of the mesopause region was recorded in October 2009. Atmospheric temperature and wind data were obtained over several observation nights. Some typical results are presented below.

Table 2 Parameters of the sodium fluorescence Doppler lidar system

\begin{tabular}{lc}
\hline \multicolumn{1}{c}{ Parameters } & Value \\
\hline Laser wavelength & $589.158 \mathrm{~nm}$ \\
Shifted frequency & $\pm 630 \mathrm{MHz}$ \\
Laser power & $\sim 1 \mathrm{~W}$ \\
Repetition rate & $30 \mathrm{~Hz}$ \\
Pulse length & $\sim 7 \mathrm{~ns}$ \\
Beam divergence & $\sim 1 \mathrm{mrad}$ \\
Telescope aperture & $40 \mathrm{~cm}$ \\
\hline
\end{tabular}

Figure 5 shows the lidar backscattering signals at 01:29 on January 12, 2010 (Beijing time is used throughout the paper). The integration time is about 3 minutes. Among the three frequency channels $f_{0}, f_{+}$and $f_{-}$, the $f_{0}$ channel signal is the strongest, about 2.5 times the strength of the other two channels. Figure 5 clearly shows that sodium atoms are mainly distributed in the range of $80-105 \mathrm{~km}$ at that time.

Figure 6 shows the temperature and sodium atom number density profiles retrieved from the data in Figure 5. In Figure 6(a), the thin solid line is the lidar temperature, and the horizontal line is the measurement error. Figure 7 shows the temperature and sodium atom number density profiles for 03:28 on January 13, 2010. Figure 8 shows the temperature and sodium atom number density profiles for 00:05 on April 3, 2010.

The magnitudes of the temperature and sodium density measurements in Figures 6-8 agree with a priori knowledge. The trend of the temperature versus height and its fluctuations illustrates obvious known atmospheric waves in the mesopause region. For simple comparison, temperatures from the MSISE00 atmosphere model are also presented in Figures 6-8. The MSISE00 empirical atmosphere model is primarily based on long-term observation data and describes the neutral temperature and density in the atmosphere from the ground to the thermosphere. It is clear in Figures 6(a)-8(a) that the lidar temperatures agree with the model temperatures in terms of their magnitudes and trend versus height; however, there are discrepancies. Especially in Figure 7(a), there is a large temperature inversion layer around $80 \mathrm{~km}$ seen in the lidar temperatures, but not in the model temperatures. The differences are easily explained in that the MSISE00 temperatures represent the statistical climate average state while the lidar temperatures represent the real atmospheric instantaneous state.

To further validate the reliability of the temperature measurements, the lidar results are compared with results obtained by the United States Thermosphere Ionosphere Mesosphere Energetics and Dynamics (TIMED) satellite.

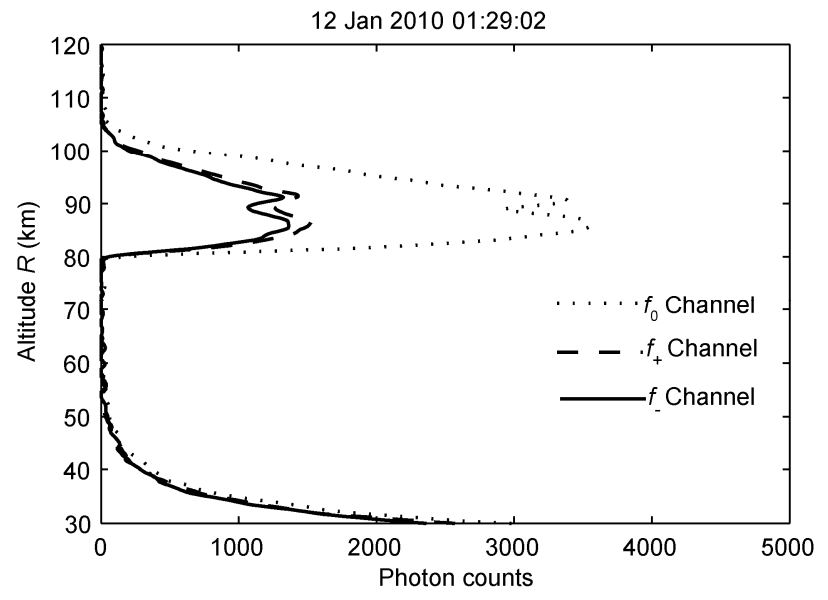

Figure 5 Sodium fluorescence Doppler lidar return signals. 

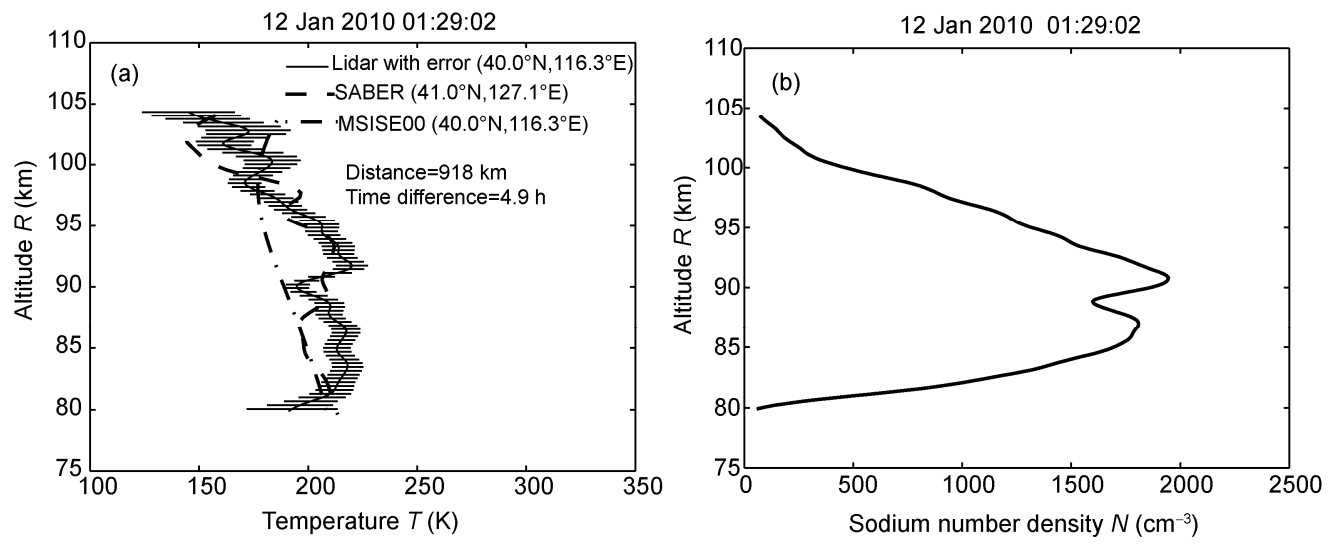

Figure 6 Measurement results at 01:29 Beijing time on January 12, 2010. (a) Temperature; (b) sodium atom number density.
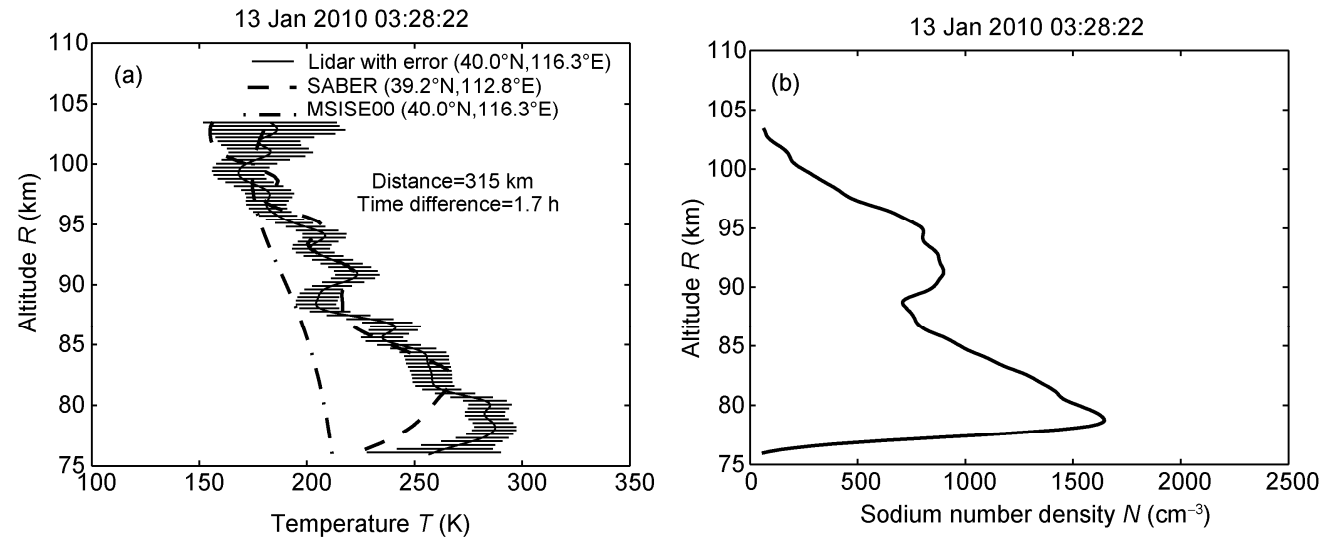

Figure 7 Measurement results at 03:28 Beijing time on January 13, 2010. (a) Temperature; (b) sodium atom number density.
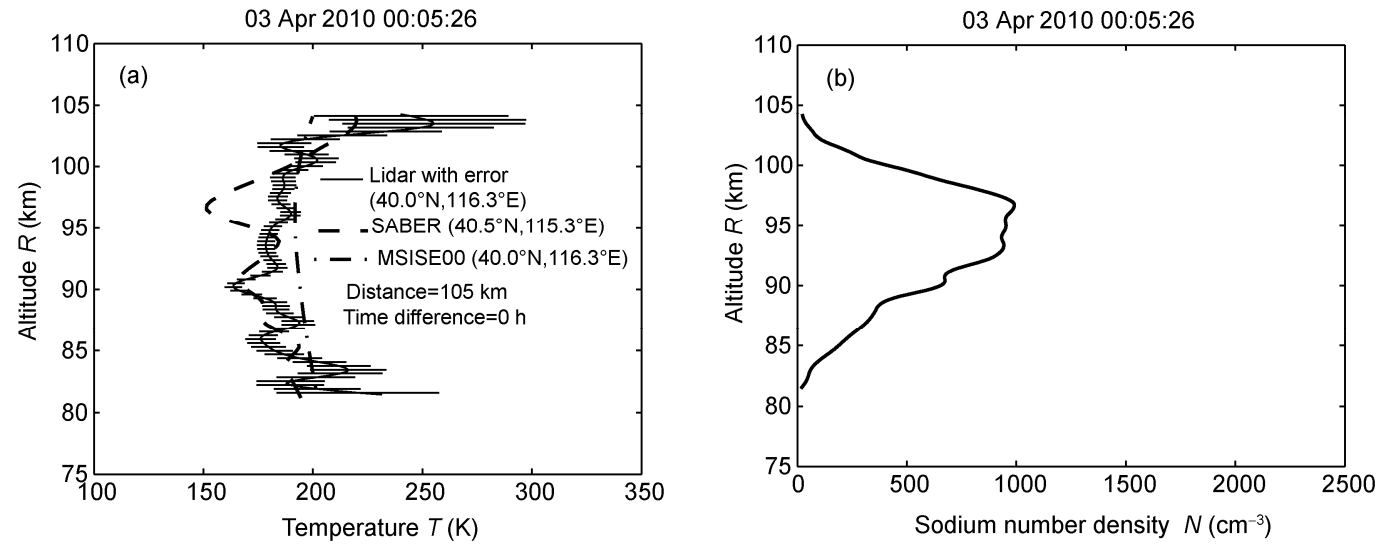

Figure 8 Measurement results at 00:05 Beijing time on April 3, 2010. (a) Temperature; (b) sodium atom number density.

The Sounding of the Atmosphere using Broadband Emission Radiometry (SABER) device aboard the TIMED satellite measures the temperature and pressure from the lower stratosphere to the lower thermosphere. The temperature vertical profiles can be derived from $15 \mu \mathrm{m}$ to $4.3 \mu \mathrm{m} \mathrm{CO}_{2}$ radiation spectra, and the measurement error is about $4-5 \mathrm{~K}$ in the range of $80-100 \mathrm{~km}[29,30]$. Comparison of TIMED/SABER results and United States sodium fluores- cence Doppler lidar results gives a difference of less than 5-10 K between 90 and $97 \mathrm{~km}[30,31]$.

The TIMED/SABER temperature data matched to the space and time of the lidar data are plotted in Figures 6(a), 7(a) and 8(a) as dashed lines. The SABER observation in Figure 6(a) was made at 20:33:54 and $41.0^{\circ} \mathrm{N}, 127.1^{\circ} \mathrm{E}$. The time difference between SABER and lidar observations is about $4.9 \mathrm{~h}$ and the spatial separation is about $918 \mathrm{~km}$. Figure 6(a) 
shows that lidar temperatures and SABER temperatures agree well, and both have obvious disturbances.

The SABER observation in Figure 7(a) was made at $01: 47: 18$ and $39.2^{\circ} \mathrm{N}, 112.8^{\circ} \mathrm{E}$. The time difference between SABER and lidar observations is about $1.7 \mathrm{~h}$ and the spatial separation is about $315 \mathrm{~km}$. There is good agreement between 81 and $100 \mathrm{~km}$. The lidar result is greater than the SABER result in the ranges $76-81 \mathrm{~km}$ and $100-103 \mathrm{~km}$. The lidar measurement error increases owing to a weakening signal between 100 and $103 \mathrm{~km}$. There is temperature inversion at $76-81 \mathrm{~km}$ in the SABER profile and a little lower in the lidar profile. There is a peak at about $79 \mathrm{~km}$ in the sodium density profile and the density changes rapidly at $76-79 \mathrm{~km}$. This phenomenon relates to chemical processes of the sodium atom. In addition, the temperature profiles have obvious disturbances as on January 12, 2010.

The SABER observation in Figure 8(a) was made at 00:05:48 and $40.5^{\circ} \mathrm{N}, 115.3^{\circ} \mathrm{E}$. The SABER and lidar observation times are similar, and the spatial separation is about $105 \mathrm{~km}$. The results are in good agreement. At $97 \mathrm{~km}$ altitude, however, the SABER temperature reaches a minimum of about $151 \mathrm{~K}$, which is $33 \mathrm{~K}$ lower than the lidar measurement.

The three comparisons of TIMED/SABER and lidar results show essential agreement. The mean deviation is about $7 \mathrm{~K}$ and the standard deviation is about $15 \mathrm{~K}$ (Figure 9).

Considering the differences in the observation times and locations of SABER and lidar measurements and the differences in their horizontal resolutions (lidar resolution of about $100 \mathrm{~m}$ and SABER resolution of about 200-300 km), and even the effects of gravity and tidal waves, the slight temperature differences are reasonable.

\section{Conclusions}

The first sodium fluorescence Doppler lidar system in China has been developed. Observation experiments measuring the atmospheric environment in the mesopause region over Beijing were conducted. The temperature and sodium number

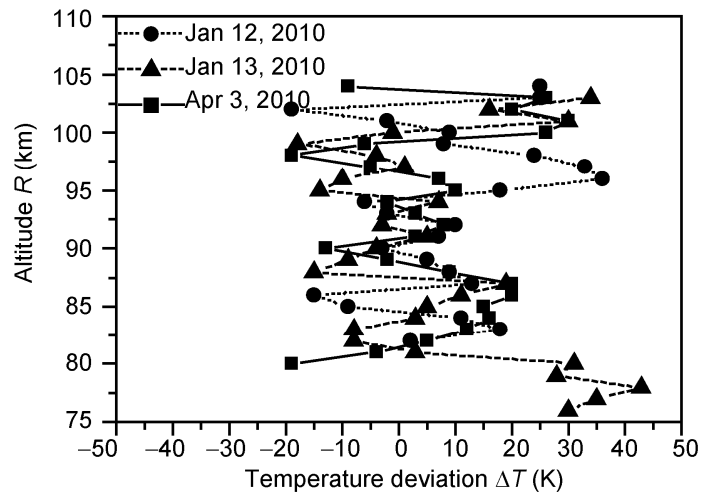

Figure 9 Temperature deviations between Lidar and TIMED/SABER results. density in the mesopause region were obtained. Comparison of the lidar temperature results with TIMED/SABER temperature results showed good agreement, indicating that the lidar results are reasonable and reliable.

We are presently upgrading the sodium fluorescence lidar system with three $1 \mathrm{~m}$ diameter telescopes and atomic filters to measure the three-dimensional wind/temperature over a whole day. This lidar system accurately measure multiple atmospheric parameters and thus benefit the study of atmospheric gravity wave features [32,33] and atmospheric instability [34,35]. The lidar system will play a significant role in research and observations of the middle and upper atmosphere or near-space environment over China.

We thank Prof. Chiao-Yao She of Colorado State University, Prof. Chu Xinzhao of University of Colorado and Prof. Gardner and Dr. Liu Zhuangren of University of Illinois at Urbana-Champaign for their assistance in developing the sodium fluorescence Doppler lidar system. This work was supported by the National Natural Science Foundation of China (40774087).

1 Weitkamp C, Walther H. Lidar: Range-Resolved Optical Remote Sensing of the Atmosphere. Singapore: Springer, 2005

2 Shibata T, Kobuchi M, Maeda M. Measurements of density and temperature profiles in the middle atmosphere with a XeF lidar. Appl Opt, 1986, 25: 685-688

3 Wu Y H, Hu H L, Hu S X, et al. Measurements of thermal profiles in the stratosphere and lower mesosphere with Rayleigh scattering lidar (in Chinese). Chin J Atmos Sci, 2002, 26: 23-29

4 Keckhut P, Chanin M L, Hauchecorne A. Stratosphere temperature measurement using Raman lidar. Appl Opt, 1990, 29: 5182-5186

5 Wu Y H, Li T, Zhou J, et al. Raman lidar measured temperature profiles in the mid-and upper troposphere (in Chinese). Chin J Atmos Sci, 2002, 26: 702-708

6 She C Y, Yu J R. Latifi H, et al. High-spectral-resolution fluorescence light detection and ranging for mesospheric sodium temperature measurements. Appl Opt, 1992, 31: 2095-2106

7 Fujii T, Fukuchi T. Laser Remote Sensing. Boca Raton: CRC Press, 2005

8 Hua D X, Uchida M, Kobayashi T. Ultraviolet Rayleigh-Mie lidar with Mie-scattering correction by Fabry-Perot etalons for temperature profiling of the troposphere. Appl Opt, 2005, 44: 1305-1314

9 Yan Z A. Research on lidar for atmospheric temperature measurement using Iodine filters (in Chinese). Dissertation for the Master Degree. Qingdao: Ocean University of China, 2007

10 Theopold F A, Bösenberg J. Differential absorption lidar measurements of atmospheric temperature profiles: theory and experiment. J Atmos Ocean Tech, 1993, 10: 165-179

11 Gardner C S. Performance capabilities of middle-atmosphere temperature lidars: Comparison of $\mathrm{Na}, \mathrm{Fe}, \mathrm{K}, \mathrm{Ca}, \mathrm{Ca}^{+}$, and Rayleigh systems. Appl Opt, 2004, 43: 4941-4956

12 Bowman M R, Gibson A J, Sandford M C W. Atmospheric sodium measured by a tuned Laser Radar. Nature, 1969, 221: 456-457

13 Gibson A J, Thomas L, Bhattachacharyya S K. Laser observations of the ground-state hyperfine structure of sodium and of temperatures in the upper atmosphere. Nature, 1979, 281: 131-132

14 Fricke K H, Zahn U, Mesopause temperatures derived from probing the hyperfine structure of the $D_{2}$ resonance line of sodium by lidar. J Atmos Terr Phys, 1985, 47: 499-512

15 She C Y, Latifi H, Yu J R, et al. Two-frequency lidar technique for mesospheric Na temperature measurements. Geophys Res Lett, 1990, 17: 929-932

16 Bills R E. Iron and Sodium Doppler/temperature lidar studies of the 
upper mesosphere. Dissertation for the Doctoral Degree. Urbana: University of Illinois at Urbana-Champaign, 1991

17 She C Y, Yu J R. Simultaneous three-frequency Na lidar measurements of radial wind and temperature in the mesopause region. Geophys Res Lett, 1994, 21: 1771-1774

18 White M A. A frequency-agile Na lidar for the measurement of temperature and velocity in the mesopause region. Doctor Dissertation for the Doctoral Degree. Fort Collins: Colorado State University, 1999

19 She C Y, Sherman J, Yuan T, et al. The first 80-h continuous lidar campaign for simultaneous observation of mesopause region temperature and wind. Geophys Res Lett, 2003, 30: 1319-1323

20 Acott P E. Mesosphere momentum flux studies over Fort Collins CO $\left(41^{\circ} \mathrm{N}, 105^{\circ} \mathrm{W}\right)$. Dissertation for the Doctoral Degree. Fort Collins: Colorado State University, 2009

21 Cheng X W, Song J, Li F Q, et al. Dual-wavelength high altitude detecting lidar technology (in Chinese). Chin J Laser, 2005, 33: 1-7

22 Yi F, Zhang S D, Zeng H, et al. Lidar observations of sporadic Na layers over Wuhan $\left(30.5^{\circ} \mathrm{N}, 114.4^{\circ} \mathrm{E}\right)$. Geophys Res Lett, 2002, 29: $1345-1348$

23 Dou X K, Xue X H, Chen T D, et al. A statistical study of sporadic sodium layer observed by sodium lidar at Hefei $\left(31.8^{\circ} \mathrm{N}, 117.3^{\circ} \mathrm{E}\right)$. Ann Geophys, 2009, 27: 2247-2257

24 Yi F, Zhang S D, Yu C M, et al. Simultaneous observations of sporadic $\mathrm{Fe}$ and $\mathrm{Na}$ layers by two closely colocated resonance fluorescence lidars at Wuhan $\left(30.5^{\circ} \mathrm{N}, 114.4^{\circ} \mathrm{E}\right)$, China. J Geophys Res, 2007, 112: D04303

$25 \mathrm{Xu} \mathrm{L}, \mathrm{Hu}$ X, Yan Z A, et al. Retrieval method of atmospheric parameters for a sodium Doppler lidar (in Chinese). Infrared Laser Eng, 2009, 38: 140-143

26 Xu L, Hu X, Cheng Y Q, et al. Simulation of echo-photon counts of a sodium Doppler ldiar and retrievals of atmospheric parameters (in Chinese). Chin J Geophys, 2010, 53: 1520-1528

27 Yan Z A, Hu X, Guo S Y, et al. Sodium atoms $D_{2}$ line Doppler-free saturation fluorescence spectra measurements (in Chinese). Acta Optica Sin, 2010, 30: 1036-1040

28 Yan Z A, Hu X, Guo S Y, et al. Long-term laser frequency stabilization for application in sodium resonance fluorescence Doppler lidar. Proc SPIE, 2009, 7382: 738232

29 Chen H B. An overview of the space-based observation for upper atmospheric research (in Chinese). Adv Earth Sci, 2009, 24: 229-241

30 Xu J Y, She C Y, Yuan W, et al. Comparision between the temperature measurements by TIMED/SABER and lidar in the midlatitude. $\mathrm{J}$ Geophys Res, 2006, 111: A10S09

31 Mertens C J, Russell III J M, Mlynczak M G, et al. Kinetic temperature and carbon dioxide from broadband infrared limb emission measurements taken from the TIMED/SABER instrument. Adv Space Res, 2009, 23: 15-27

32 Hu X, Liu A, Gardner C, et al. Characteristics of quasi-monochromatic gravity waves observed with a lidar in mesopause region at Starfire Optical Range, NM. Geophys Res Lett, 2002, 29: 22-122-4

33 Hu X, Gardner C, Liu A, et al. Propagation directions of the mesospheric monochromatic inertial gravity waves observed with a lidar at SOR, NM. Proc SPIE, 2003, 4893: 237-244

34 Liu A, Roble R G, Hecht J H, et al. Unstable layers in the mesopause region observed with $\mathrm{Na}$ lidar during the turbulent oxygen mixing experiment (TOMEX) campaign. J Geophys Res, 2004, 109: D02S02

35 Tu C, Hu X, Yan Z A, et al. First imaging observation of the gravity waves in the mesopause region in China. Chinese Sci Bull, 2010, 55: $539-543$

Open Access This article is distributed under the terms of the Creative Commons Attribution License which permits any use, distribution, and reproduction in any medium, provided the original author(s) and source are credited. 